\title{
SEBARAN POTENSI HUTAN PINUS DAN PERANNYA TERHADAP PERBAIKAN KONDISI HUTAN DI PROVINSI SULAWESI SELATAN
}

\author{
Distribution Of Pine Forest Potential and Their Role on Improvement of Forest \\ Conditions in South Sulawesi Province
}

\author{
Tajuddin $^{\mathbf{a}}$, Doddy Ari Suryanto ${ }^{b}$ \\ ${ }^{a)}$ Balai Pengelolaan Hutan Produksi Wilayah XIII Makassar, Jl. Perintis Kemerdekaan Km. 9 Makassar \\ ${ }^{b)}$ Fakultas Teknik Sipil dan Perencanaan Universitas Gunadarma, Jl. Raya Outer Ringroad, \\ RT.7/RW.14, Cengkareng Timur, Jakarta \\ Email: tajuddin.agathis@gmail.com,doddyaris@staff.gunadarma.ac.id
}

Diterima: 20 November 2021, Direvisi: 02 Desember 2021, Disetujui: 24 Januari 2022

DOI: 10.31849 /forestra.v17i1.8448

\section{ABSTRACT}

Pine forests in South Sulawesi are evidence of the success of the government's reforestation program. The purpose of this study was to describe a map of the distribution of pine forests and their role in improving forest conditions in South Sulawesi Province. Mapping of the distribution of pine forests through an overlay of village administrative maps that have pine potential based on information from informants with maps of forest areas. Furthermore, an analysis of changes in land cover and land use to determine the role of pine forests in improving forest conditions, in locations identified as having pine forest potential. We find that the potential for pine forests is spread across 18 districts/cities in South Sulawesi Province. The pine forest has increased people's income from the economic aspect and improved the condition of the forest from the ecological aspect. The choice of pine species that provide economic benefits makes people tend to maintain pine stands because they can be used as a source of livelihood.

Keywords: pine forest, reforestation, land cover

\begin{abstract}
ABSTRAK
Hutan pinus yang terdapat di Sulawesi Selatan menjadi salah satu bukti keberhasilan program reboisasi yang dilakukan oleh pemerintah. Tujuan penelitian ini untuk menggambarkan peta sebaran hutan pinus dan perannya dalam perbaikan kondisi hutan di Provinsi Sulawesi Selatan. Metode yang digunakan dalam pemetaan sebaran hutan pinus adalah melalui overlay peta administrasi desa yang memiliki potensi pinus berdasarkan informasi dari informan dengan peta kawasan hutan. Selanjutnya, untuk mengetahui peran hutan pinus dalam perbaikan kondisi hutan, maka dilakukan analisis perubahan tutupan dan penggunaan lahan pada lokasi yang teridentifikasi memiliki potensi hutan pinus. Hasil penelitian menunjukkan bahwa potensi hutan pinus di Provinsi Sulawesi Selatan terdapat di 18 kabupaten/kota. Hutan pinus tersebut telah meningkatkan pendapatan masyarakat dari aspek ekonomi, dan memperbaiki kondisi hutan dari aspek ekologi. Pemilihan jenis pinus yang memberikan manfaat ekonomi membuat masyarakat cenderung untuk menjaga tegakan pinus karena dapat dijadikan sebagai sumber mata pencaharian.
\end{abstract}

Kata kunci: hutan pinus, reboisasi, tutupan lahan 


\section{PENDAHULUAN}

Kondisi hutan yang telah mengalami kerusakan akibat deforestasi dan degradasi menjadi perhatian pemerintah untuk segera dipulihkan. Lahan-lahan hutan yang rusak harus segera direhabilitasi melalui kegiatan penanaman yang diwujudkan dalam program reboisasi. Nawir . (2008) mendefinisikan reboisasi sebagai kegiatan penanaman untuk memperbaiki atau merehabilitasi kawasan hutan negara yang mengalami kerusakan/degradasi dan mengembalikan fungsi hutan.

Dalam pelaksanaan reboisasi, pohon pinus (Pinus merkusii) menjadi salah satu pilihan yang banyak digunakan. Sebelum kemerdekaan, pinus telah mulai ditanam dalam program reboisasi khususnya yang dilaksanakan di Pulau Jawa. Pinus juga memiliki sifat genetis yang baik sehingga dapat dengan mudah tersebar ke banyak tempat di Indonesia (Indrajaya \& Handayani, 2008; Wijayanto \& Nurmadina, 2021). Secara khusus di Provinsi Sulawesi selatan, penanaman pinus sebagai tanaman reboisasi telah dimulai sejak tahun 1948 di Kabupaten Tana Toraja (Sallata, 2013). Perluasan tanaman pinus ke berbagai kabupaten di Sulawesi Selatan melalui program reboisasi yang dimulai sejak tahun 1976/1977 dan dibiayai dengan dana Inpres.

Dari segi manfaat, pohon pinus memiliki potensi kayu dan getah yang dapat dimanfaatkan oleh masyarakat. Selain itu, dari sisi ekologis, hutan pinus dapat memberi manfaat hidrologis yang baik dalam mencegah erosi (Sallata, 2013). Hingga saat ini, pemanfaatan terbesar dari hutan pinus adalah penyadapan getah. Getah dari pohon pinus tersebut berbentuk cairan asam resin yang dapat diolah lebih lanjut menjadi gondorukem dan terpentin yang bermanfaat dalam mendukung industri kosmetik, obatobatan dan makanan.

Selanjutnya, hutan pinus yang ada di Provinsi Sulawesi Selatan menjadi bukti keberhasilan program reboisasi di Sulawesi Selatan. Manfaatnya telah banyak dirasakan oleh masyarakat khususnya dalam peningkatan perekonomian. Hutan pinus telah memberikan manfaat kepada masyarakat, antara lain: kayu, getah, biji (sebagai sumber benih) dan manfaat jasa lingkungan berupa lokasi wisata alam (Sallata, 2013; Tajuddin, 2021).

Berbagai penelitian yang terkait dengan hutan pinus pada umumnya menguraikan berbagai manfaat dan peran 
getah pinus dalam peningkatan kesejahteraan masyarakat (Martono, 2009; Mulyadi, 2016; Sophian, 2016; Suwaji et al., 2017). Selain itu, terdapat penelitian yang membahas peran hutan pinus dalam penyerapan karbon (Indrajaya, 2016) dan teknik penyadapan getah pinus (Lempang, 2017).

Mengingat bahwa hutan pinus yang tumbuh di Sulawesi Selatan merupakan tanaman reboisasi yang bertujuan untuk meningkatkan tutupan hutan dan memberikan manfaat kepada masyarakat setempat, maka penting untuk mengetahui sebaran potensinya dan melihat perannya dalam perbaikan kondisi tutupan hutan. Oleh karena itu, artikel ini menguraikan sebaran potensi hutan pinus di Provinsi Sulawesi Selatan melalui pemetaan hutan pinus dan perannya dalam perbaikan kondisi hutan yang dilakukan menggunakan analisis perubahan tutupan lahan.

\section{METODE PENELITIAN}

Penelitian ini menggunakan data primer dan data sekunder. Data primer berupa data lokasi hutan pinus diperoleh dari hasil observasi lapangan di beberapa kabupaten dan informasi dari 19 orang informan yang merupakan petugas kehutanan di Kesatuan Pengelolaan Hutan (KPH), pemilik izin Pemungutan Hasil Hutan Bukan Kayu (IPHHBK) dan masyarakat di sekitar hutan. Pemetaan potensi hutan pinus menggunakan data sekunder berupa data administrasi desa yang di keluarkan oleh Badan Informasi Geospasial (BIG) Tahun 2014, dan Peta kawasan hutan terakhir yang diterbitkan oleh Kementerian LHK pada tahun 2019. Selanjutnya, dilakukan overlay peta administrasi desa yang memiliki potensi pinus berdasarkan informasi dari informan dengan peta kawasan hutan menggunakan software ArcGIS 10.7.1.

Untuk analisis perubahan tutupan lahan menggunakan data sekunder berupa peta hasil interpretasi citra Landsat 7 dan Landscat 8 selama 26 terakhir (liputan tahun 1990, 2003 dan 2016) yang diterbitkan oleh Kementerian LHK. Selanjutnya, analisis perubahan tutupan lahan menggunakan software Arcgis 10.7.1. dengan metode change detection yaitu dengan teknik post classification comparison (PCC). Singh (1989) menunjukkan bahwa teknik post classification comparison (PCC) adalah metode deteksi perubahan yang paling jelas untuk menganalisis perubahan tutupan lahan 
yang terjadi pada hasil klasifikasi citra $t_{1}$ dengan hasil klasifikasi citra $\mathrm{t}_{2}$.

Kelas tutupan lahan menggunakan SNI tentang kelas penutupan lahan yang dipakai oleh Kementerian LHK antara lain: Hutan lahan kering primer (Hp), Hutan lahan kering sekunder (Hs), Hutan tanaman (Ht), Belukar (B), Savana/Padang rumput (S), Pertanian lahan kering campur semak $(\mathrm{Pc})$, Perkebunan $(\mathrm{Pk})$, Pemukiman (Pm), Areal terbuka (T), Tertutup Awan (Aw), Tubuh air (A), Belukar rawa (Br), Pertanian lahan kering $(\mathrm{Pt})$ dan Sawah $(\mathrm{Sw})$. Dalam penelitian ini, kelas penutupan lahan untuk $\mathrm{Pk}, \mathrm{Pm}, \mathrm{T}, \mathrm{Aw}, \mathrm{A}, \mathrm{Br}, \mathrm{Pt}$ dan $\mathrm{Sw}$ dikelompokkan ke kelas Tutupan Lain (TL).

\section{HASIL DAN PEMBAHASAN}

\section{Sebaran Potensi Hutan Pinus}

Pinus (Pinus merkusii) memiliki nama daerah antara lain: damar bunga, pinus dan tusam uyam. Tinggi pohon bervariasi dari 20-40 meter dengan bebas cabang sekitar 2-23 meter, batang pohon tidak berbanir dengan diameter hingga $100 \mathrm{~cm}$. Batang memiliki kulit yang kasar dengan warna coklat-kelabu hingga coklat tua, tidak mengelupas serta alur yang dalam lebar (Martawijaya et al., 1987). Pinus ditemukan pertama kali di daerah Sipirok, Tapanuli Selatan oleh Dr. F. R. Junghuhn yang merupakan ahli botani berkebangsaan Jerman pada tahun 1841 .

Pinus adalah tanaman yang dikenal sangat baik dan telah digunakan dalam kegiatan reboisasi dan penghijauan sejak tahun 60-an oleh pemerintah melalui Kementerian Kehutanan (Sallata, 2013). Pinus juga dapat tumbuh di banyak tempat karena memiliki sifat-sifat genetis yang baik (Indrajaya \& Handayani, 2008). Selain itu, pinus adalah jenis pohon yang tergolong cepat tumbuh dan dalam proses penanaman tidak membutuhkan persyaratan khusus. Oleh karena itu, pinus dapat tersebar hingga ke wilayah selatan khatulistiwa (Corryanti \& Rahmawati, 2015).

Sulawesi Selatan menjadi salah satu daerah penyebaran pinus yang dikembangkan secara masif dalam program reboisasi. Hasil pemetaan potensi hutan pinus menghasilkan peta sebaran hutan pinus yang diperoleh berdasarkan hasil overlay peta administrasi desa yang memiliki potensi hutan pinus dengan peta kawasan hutan (Gambar 1). Peta sebaran potensi hutan pinus yang dihasilkan sebenarnya merupakan peta identifikasi tentang keberadaan hutan pinus 
di Sulawesi Selatan. Selanjutnya untuk memperoleh luasan dan lokasi yang lebih detail diperlukan pemetaan yang didasarkan pada hasil pengukuran lapangan atau menggunakan citra satelit resolusi tinggi/citra hasil drone. Walaupun demikian, peta sebaran potensi hutan pinus ini dapat dijadikan sebagai refensi utama dalam pemetaan yang lebih detail.

Selain itu, peta sebaran hutan pinus di Sulawesi Selatan menjadi salah satu sumber informasi yang dapat digunakan oleh dunia usaha untuk melakukan kegiatan usaha seperti getah pinus atau ekowisata. Jenis usaha ini memiliki kecenderungan yang terus meningkat di Sulawesi Selatan karena semakin kurangnya potensi hasil hutan kayu, prospeknya yang menjanjikan dan telah terbukti meningkatkan pendapatan masyarakat di sekitar hutan.

Jika dilihat dari fungsi hutan, keberadaan hutan pinus di Sulawesi Selatan berada pada kawasan hutan konservasi, hutan lindung dan hutan produksi. Secara umum, hutan pinus tersebut merupakan hasil reboisasi dan dalam jumlah yang terbatas merupakan tanaman masyarakat di lahan milik atau merupakan tanaman yang tumbuh secara alami (Sallata, 2013). 
Wahana Forestra: Jurnal Kehutanan Vol. 17 No. 1 Januari 2022

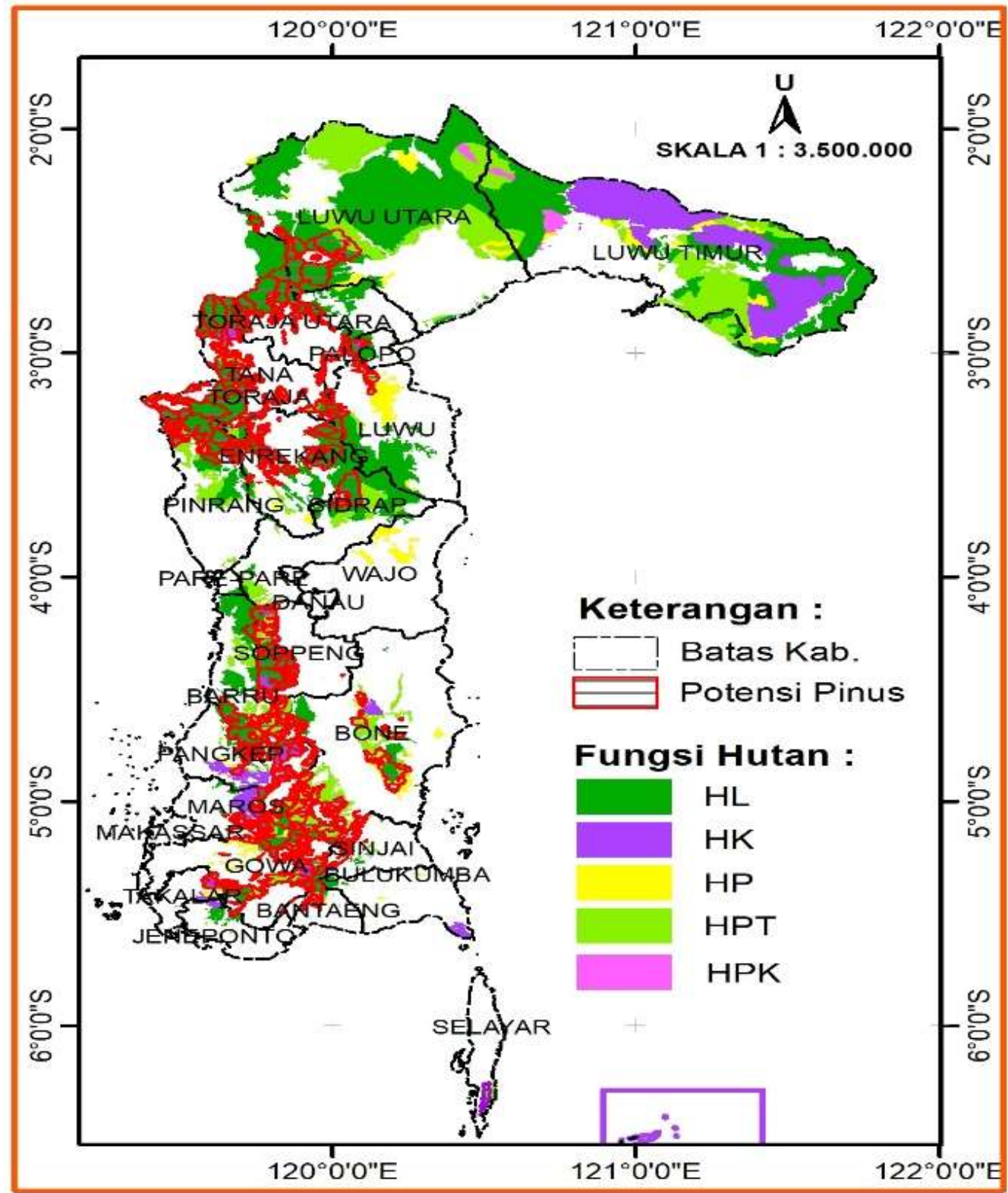

HL: Hutan lindung, HK: Hutan konservasi, HP: Hutan produksi tetap; HPT: Hutan produksi terbatas, HPK: Hutan produksi yang dapat di konversi

Gambar 1. Peta sebaran hutan pinus di Sulawesi Selatan

Berdasarkan hasil pemetaan diperoleh informasi bahwa potensi hutan pinus di Sulawesi Selatan tersebar pada 18
Kabupaten/Kota dari 24 Kabupaten/Kota. Selanjutnya jika dilihat dari wilayah administrasi desa, maka hutan pinus tersebar 
di 321 desa atau 10,5\% dari jumlah desa yang ada di Sulawesi Selatan. Sebaran jumlah desa yang memiliki potensi hutan pinus sebagaimana disajikan dalam bentuk grafik pada Gambar 2. Dari grafik tersebut, terlihat bahwa 6 kabupaten yang memiliki potensi pinus tertinggi adalah: Tana Toraja, Toraja Utara, Enrekang, Gowa, Maros dan Bone.

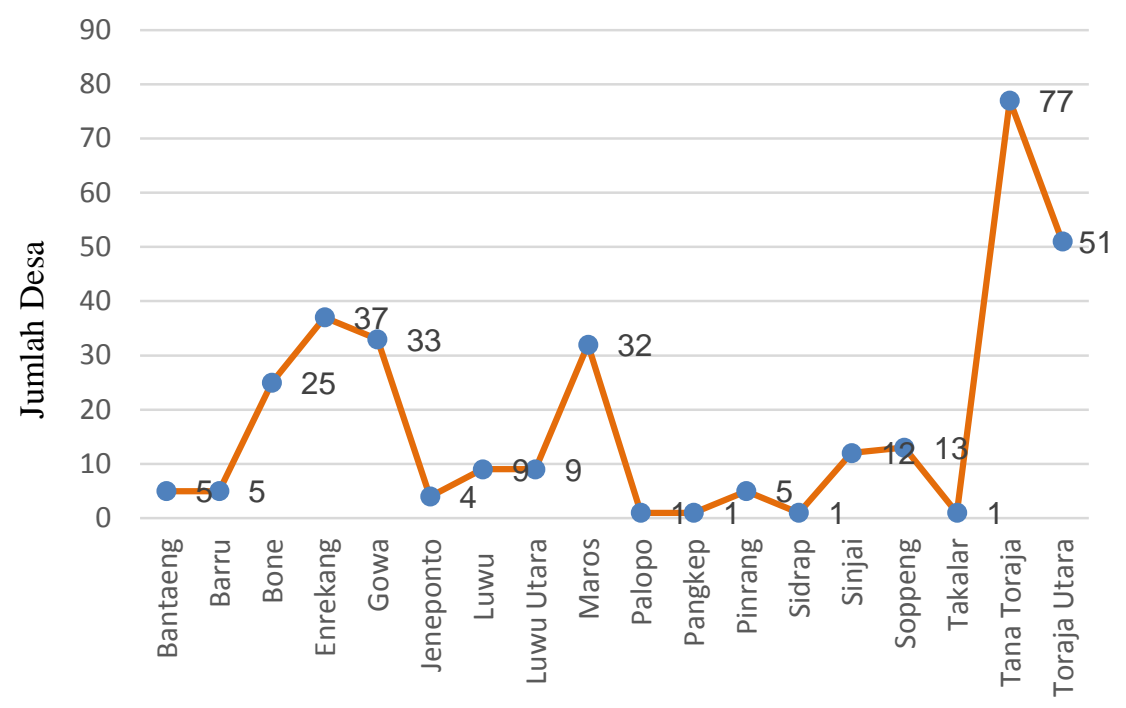

Kabupaten

Gambar 2. Jumlah desa yang memiliki potensi pinus pada masing-masing kabupaten

2. Perubahan tutupan dan penggunaan lahan

Habitat hutan tropis terus menurun secara global, dengan konsekuensi serius bagi kelestarian lingkungan. Hutan tropis di Asia Tenggara termasuk di Indonesia merupakan salah satu bagian paling menantang di dunia untuk mempelajari masalah perubahan bentang alam. Hal ini disebabkan karena kepadatan penduduk yang tinggi di kawasan ini menimbulkan ancaman besar terhadap tutupan hutan (Southworth $e t$ al., 2012). Perubahan tutupan lahan dan penggunaan lahan telah mempengaruhi penyediaan jasa ekosistem untuk manusia dan habitat satwa liar (Mmbaga et al., 2017). Oleh karena itu, analisis perubahan tutupan lahan dan diakui sebagai salah satu alat yang paling efektif untuk pengelolaan sumber daya lingkungan. Mengingat kompleksitas perubahan tutupan lahan yang timbul, maka strategi pemantauan lingkungan tingkat lanskap yang akurat berdasarkan 
penginderaan jarak jauh dan SIG dapat memainkan peran kunci untuk pengelolaan sumber daya lingkungan (Alphan et al., 2009).

Analisis perubahan tutupan dan penggunaan lahan dapat digunakan untuk melihat peran hutan pinus yang merupakan hutan tanaman hasil reboisasi terhadap perbaikan kondisi hutan. secara umum, hasil analisis perubahan tutupan lahan pada lokasi yang teridentifikasi memiliki potensi pinus di Sulawesi Selatan menunjukkan adanya dinamika yang heterogen (Gambar 3).

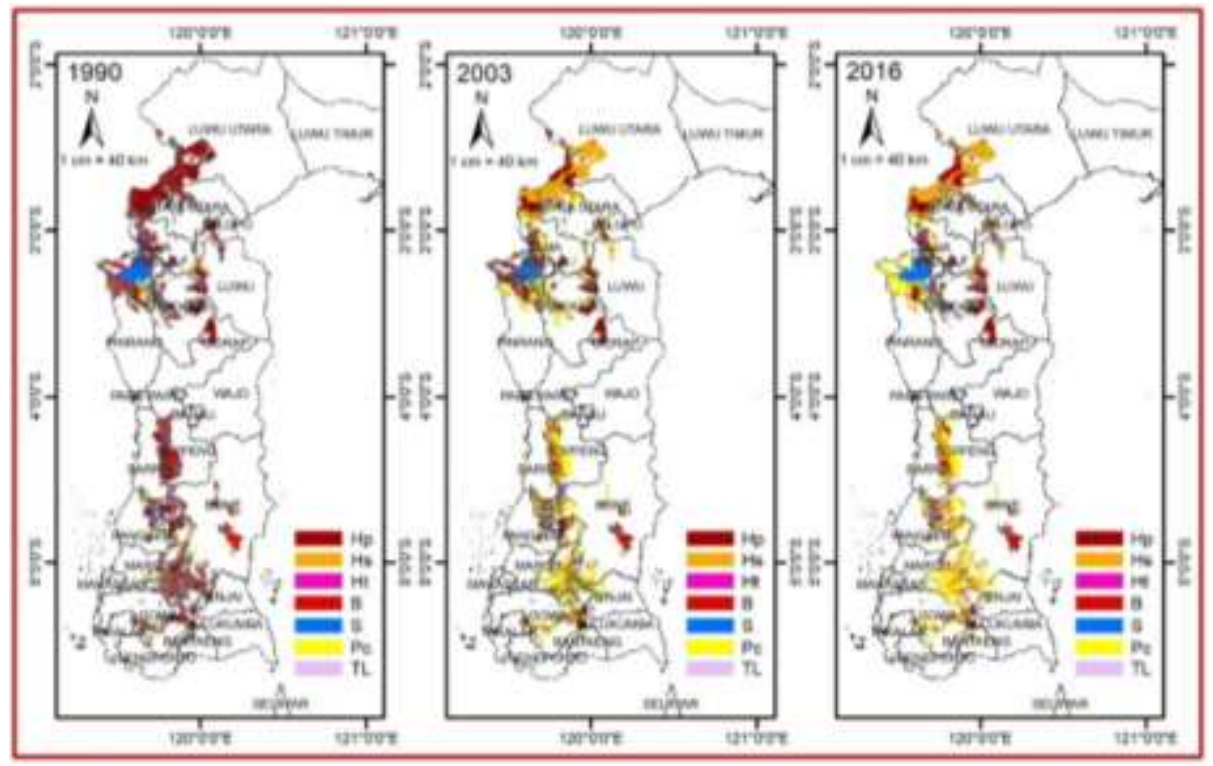

Hp: Hutan lahan kering primer; Hs: Hutan lahan kering sekunder; Ht: Hutan tanaman,

B: Belukar; S: Savana, Pc: Pertanian lahan kering campur semak; TL: Tutupan lain

Gambar 3. Peta perubahan tutupan lahan untuk 6 kelas penutupan lahan utama

Perubahan yang paling mencolok terutama pada rentang waktu antara tahun 1990-2003. Hal ini terlihat dengan berkurangnya hutan primer (Hp) yang semula 243.8585 hektar (pada tahun 1990) menjadi 68.292 hektar (pada tahun 2003).
Demikian juga dengan tutupan lahan berupa Belukar (B) yang luasnya berkurang secara signifikan dari 190.087 hektar (pada tahun 1990) menjadi 101.361 hektar (pada tahun 2003) (Tabel 1). Di pihak lain, luas hutan sekunder (Hs) dan areal pertanian lahan 
kering campur $(\mathrm{Pc})$ mengalami kenaikan pada periode yang sama. Hs mengalami kenaikan dari 12.324 hektar (pada tahun 1990) menjadi 176.478 hektar (pada tahun 2003). Pada kurun waktu yang sama, Pc mengalami kenaikan dari 22.067 hektar (pada tahun 1990) menjadi 125.380 hektar (pada tahun 2003). Dengan hasil ini, terlihat bahwa tutupan lahan pada kurun waktu 1990-2003 berupa Hp yang berubah menjadi menjadi Hs dan B berubah menjadi Pc.

Tabel 1. Perubahan tutupan dan penggunaan lahan periode 1990-2016

\begin{tabular}{cccc}
\hline Tutupan & \multicolumn{3}{c}{ Tahun (Hektar) } \\
\cline { 2 - 4 } Lahan & 1990 & 2003 & 2016 \\
\hline Hp & 243.858 & 68.292 & 63.819 \\
Hs & 12.324 & 176.478 & 177.389 \\
Ht & 9.126 & 9.278 & 9.368 \\
B & 190.087 & 101.361 & 101.843 \\
S & 37.103 & 37.151 & 35.127 \\
Pc & 22.067 & 125.380 & 126.758 \\
TL & 8.291 & 4.917 & 8.554 \\
\hline Jumlah & 522.858 & 522.858 & 522.858 \\
\hline
\end{tabular}

Perubahan tutupan lahan tersebut menunjukkan semakin banyaknya kawasan hutan yang terdegradasi dan semakin meningkatnya alih fungsi lahan hutan untuk berbagai keperluan terutama untuk areal pertanian dan pemukiman. Hal ini terjadi hampir diseluruh dunia karena tuntutan dan jumlah masyarakat yang terus meningkat (Antoko et al, 2008; Linh et al., 2012).
Gangguan lahan tersebut mempengaruhi proses dan jasa ekosistem yang penting, yang dapat memiliki konsekuensi jangka panjang dan luas hutan yang menyediakan banyak jasa ekosistem. Selain itu, pola perubahan tutupan lahan merupakan dampak dari adaptasi praktik penggunaan lahan tradisional petani dengan kondisi biofisik dan aksesibilitas serta ketersediaan sumber daya (Käyhkö et al., 2015).

Walaupun diakui bahwa dampak perubahan tutupan hutan tidak selalu negatif, karena banyak bentuk perubahan penggunaan/tutupan lahan akan terkait dengan peningkatan yang berkelanjutan dalam produksi makanan dan serat (Lambin et al., 2003). Hal ini disebabkan karena lahan adalah salah satu faktor utama untuk kegiatan produksi selain faktor modal dan tenaga kerja serta menjadi input yang sangat berperan untuk kepentingan produksi pangan pemukiman. Dengan demikian, penggunaan lahan adalah tulang punggung ekonomi pertanian dan memberikan manfaat ekonomi dan sosial yang besar.

Selanjutnya, perubahan tutupan lahan pada penutupan lahan savana (S) dan hutan tanaman (Ht) tidak menunjukkan perubahan 
yang signifikan. Pada Ht menunjukkan kecenderungan yang semakin meningkat meskipun jumlahnya masih termasuk relatif kecil. Namun, fakta ini menunjukkan bahwa hutan tanaman yang ditanam dalam program reboisasi dapat memperbaiki kondisi tutupan hutan. Kondisi ini sangat ditentukan oleh pemilihan jenis tanaman yang memiliki manfaat ekonomis bagi masyarakat seperti jenis pinus. Masyarakat akan cenderung untuk menjaga tegakan pinus karena dapat dijadikan sebagai sumber mata pencaharian.

Secara khusus di Sulawesi Selatan, pinus telah menjadi salah satu sumber HHBK yang dapat mendukukung kelestarian hutan. Hasil HHBK berupa getah pinus telah meningkatkan penghasilan masyarakat dan membuka lapangan kerja baik bagi masyarakat Sulawesi Selatan maupun pendatang dari luar pulau (Satil et al., 2011; Sallata, 2013; Tajuddin, 2021; Martono, 2009).

\section{KESIMPULAN DAN SARAN}

\section{A. Kesimpulan}

Sulawesi Selatan memiliki potensi hutan pinus hasil reboisasi yang cukup besar dan tersebar di 18 kabupaten/kota. Enam kabupaten yang memiliki potensi pinus tertinggi adalah: Tana Toraja, Toraja Utara, Enrekang, Gowa, Maros dan Bone. Hutan pinus tersebut telah meningkatkan pendapatan masyarakat dari aspek ekonomi, dan memperbaiki kondisi hutan dari aspek ekologi. Perubahan tutupan lahan untuk Hutan tanaman (Ht) menunjukkan kecenderungan yang semakin meningkat menunjukkan perannya yang positif dalam perbaikan kondisi hutan. Oleh karena itu, pemilihan jenis tanaman yang memberi dampak pada perbaikan mata pencaharian masyarakat menjadi salah satu kunci keberhasilan reboisasi.

\section{B. Saran}

Mengingat bahwa pemetaan potensi hutan pinus dalam penelitian ini masih bersifat hasil identifikasi maka diperlukan pemetaan yang lebih detail untuk memperoleh luasan dan lokasi yang lebih akurat dengan menggunakan hasil pengukuran lapangan atau menggunakan citra satelit resolusi tinggi/citra hasil drone.

\section{UCAPAN TERIMA KASIH}

Ucapan terima kasih kepada para pihak yang telah mendukung penulis dalam memperoleh data dan informasi yang 
digunakan dalam penelitian ini sehingga dapat terlaksana sesuai dengan rencana.

\section{DAFTAR PUSTAKA}

Alphan, H., Doygun, H., \& Unlukaplan, Y. I. (2009). Post-classification comparison of land cover using multitemporal Landsat and ASTER imagery: The case of Kahramanmaras, Turkey. Environmental Monitoring and Assessment, 151(1-4), 327-336. https://doi.org/10.1007/s10661-0080274-x

Antoko, B. S., Sanudin, \& Sukmana, A. (2008). Perubahan Fungsi Hutan di Kabupaten Asahan, Sumatera Utara. Info Hutan, 5, 307-316.

Corryanti, \& Rahmawati, R. (2015). Terobosan Memperbanyak Pinus (Pinus merkusii). Puslitbang Perum Perhutani.

Indrajaya, Y. (2016). Manfaat Lingkungan Penyerapan Karbon Hutan Pinus Pada Beberapa Kelas Tempat Tumbuh Di Jawa. Prosiding Seminar Nasional Geografi UMS 2016, 123-130.

Indrajaya, Y., \& Handayani, W. (2008). Potensi Hutan Pinus Merkusii Jungh. Et De Vriese Sebagai Pengendali Tanah Longsor Di Jawa. Info Hutan, V(3), 231-240.

Käyhkö, N., Fagerholm, N., \& J. Mzee, A. (2015). Local farmers' place-based forest benefits and government interventions behind land and forest cover transitions in Zanzibar, Tanzania. Journal of Land Use Science, 10(2), $150-173$.

https://doi.org/10.1080/1747423X.201 3.858784
Lambin, E. F., Geist, H. J., \& Lepers, E. (2003). Dynamics Of Land-Use and Land-Cover Change in Tropical Regions. Annual Review of Environment and Resources, 28(1), 205-241. https://doi.org/10.1146/annurev.energy .28 .050302 .105459

Lempang, M. (2017). Studi Penyadapan Getah Pinus Cara Bor dengan Stimulan H2SO4. Jurnal Penelitian Hasil Hutan, $35(3)$, 221-230. https://doi.org/10.20886/jphh.2017.35. 3.221-230

Linh, N. H. K., Erasmi, S., \& Kappas, M. (2012). Quantifying Land Use / Cover Change and Landscape Fragmentation in Danang City, Vietnam : 1979-2009. XXII ISPRS Congress, XXXIX(September), 501-506.

Martawijaya, A., Kartasujana, I., Mandang, Y. I., Prawira, S. A., \& Kadir, K. (1987). Atlas Kayu Indonesia Jilid II. Badan Peneltian dan Pengembangan Kehutanan.

Martono, D. S. (2009). Konstribusi Pendapatan dari Penyadapan Getah Pinus Terhadap Pendapatan Totalnya : Studi Kasus di RPH Guyangan BKPH Ponorogo Barat KPH Lawu Ds Perum Perhutani Unit II Jawa Timur. AgriTek, 10(2), 74-79.

Mmbaga, N. E., Munishi, L. K., \& Treydte, A. C. (2017). How dynamics and drivers of land use/land cover change impact elephant conservation and agricultural livelihood development in Rombo, Tanzania. Journal of Land Use Science, 12(2-3), 168-181. https://doi.org/10.1080/1747423X.201 7.1313324 
Mulyadi, R. (2016). Membangun kemitraan melalui hasil hutan bukan kayu. USAID Lestari: Cerita Dari Lapangan.

Nawir, A. A., Murniati, \& Rumboko, L. (Eds.). (2008). Rehabilitasi hutan di Indonesia: Akan kemanakah arahnya setelah lebih dari tiga dasawarsa? Center for International Forestry Research (CIFOR).

Sallata, M. K. (2013). Pinus (Pinus merkusii Jungh Et De Vriese) dan Keberadaannya di Kabupaten Tana Toraja, Sulawesi Selatan. Info Teknis EBONI, 10(2), 85-98.

Satil, F., Selvi, S., \& Polat, R. (2011). Ethnic uses of pine resin production from Pinus brutia by native people on the Ethnic uses of pine resin production from Pinus brutia by native people on the Kazda ğ Mountain ( Mt . Ida ) in Western Turkey. Journal of Food, Agriculture \& Environment, 9(3\&4), 1059-1063.

Singh, A. (1989). Review article digital change detection techniques using remotely-sensed data. International Journal of Remote Sensing, 10:6, 9891003,. $\quad$ https://doi.org/10.1080/ 01431168908903939

Sophian, D. H. (2016). Keefektifan Penerimaan Sektor Kehutanan Produksi Getah Pinus Dalam Meningkatkan Pendapatan Asli Daerah Kabupaten Gowa. Skripsi. Fakultas Ilmu Sosial, Universitas Negeri Makassar. (Tidak Dipublikasikan).

Southworth, J., Nagendra, H., \& Cassidy, L. (2012). Forest transition pathways in Asia - studies from Nepal, India, Thailand, and Cambodia. Journal of Land Use Science, 7(1), 51-65.
https://doi.org/10.1080/1747423X.201 0.520342

Suwaji, S., Lamusa, A., \& Howara, D. (2017). Analisis Pendapatan Petani Penyadap Getah Pinus Di Desa Tangkulowi Kecamatan Kulawi Kabupaten Sigi Sulawesi Tengah. E-J. Agrotekbis, 5(1), 127-133.

Tajuddin. (2021). Pemanfaatan Getah Pinus dan Perannya Terhadap Penghidupan Masyarakat di Provinsi Sulawesi Selatan. ULIN: Jurnal Hutan Tropis, 5(1), 9. https://doi.org/10.32522/ ujht.v5i1.4151

Wijayanto, A., \& Nurmadina. (2021). Produktivitas Resin Pinus Merkusii Jungh Et De Vriese pada Kelas Umur dan Ketinggian Tempat Tumbuh yang Berbeda. Wahana Forestra: Jurnal Kehutanan, 16(2), 102-112. https://doi.org/10.31849/forestra.v16i2 .6765 